\title{
The Study on Technology Innovation of Chinese Enterprises
}

\section{by Regression Analysis}

\author{
Ziyan Zhang \\ College of Economic \& Management, Sichuan Agricultural University \\ 46 Xin Kang Street, Ya'an 625014, China \\ E-mail: 510joy@163.com \\ Xungang Zheng (Corresponding author) \\ College of Economic \& Management, Sichuan Agricultural University \\ 46 Xin Kang Street, Ya'an 625014, China \\ E-mail: zxg9@163.com
}

\begin{abstract}
According to China Science and Technology Data in recent years, we use Multiple Regression to analysis the influencing factors of technology innovation, and demonstrate the impact of significant and non-significant factors about China's investment expenditures related policies for technological innovation, so as to enhance China's technological innovation capability and to promote domestic economic development play a guidance and reference.
\end{abstract}

Keywords: China, Technological innovation, Regression analysis

\section{Background Information}

With the continuous economic development, the core of competitions is gradually shifted from quantity to quality. The quality is the essence of technology. For an enterprise that wants to get more and better developments, technological progress and innovation has become the main source of competitive advantage and methods. In the ever-changing tide of technology development, effective technology innovation has become the inevitable subject of modern enterprises. It is necessary for China, a developing country, to improve capacity for independent innovation.

From the literature, it can be found that the researches of technology innovation have been carried out in following aspects:

Zhao Yong and Ye Liang (2007) analyze disadvantage of two hierarchical evaluation model of technological innovation capability of enterprise. According to them, one hierarchical evaluation model has been established and the harmful effects due to multiple linearity among in evaluation indexes were corrected. The ridge regression approach has been applied to data processing and the influences of different evaluation indexes on technological innovation capability of enterprise can be properly confirmed. It has offered the important basis for improving technology innovation capability of enterprise.

Xie HongmingandWang Cheng (2007) examine the relationships between the internal social capital organizational culture and knowledge integration. Using Structural Equation Model with the data of 148 companies in South China they believe that: organizational culture has a positive indirect impact on performance by knowledge integration and technical innovation; knowledge integration has 4 positive indirect impact on performance by technical innovation. The research will put forward some suggestion for Chinese firms to improve technical innovation capability.

Zeng Zhu (2008) interprets the effect of technological innovation on America' economic growth, and discusses the evolving course and characteristics of innovation policy. Based on analyzing the influencing factors, he points that it puts forward the direction for further efforts.

Du Xiufang and Yan Xiaofei (2008) have indicated that China's economy is in a high-speed development, but the regional development are imbalanced. One of the main causes is that the imbalanced technological innovation capacity. In order to understand the differences of regional technological innovation capacity more, 
this paper builds up an evaluating indicator system which is accomplished on the basis of previous studies and the principles of all-around perspectives, close relationship and data accessibility through careful comparison and selection. Subsequently, by adopting statistics of 2006, an empirical study on the capacity of scientific study and technology innovation in 30 provinces, municipalities and autonomous regions of China is made and relevant analysis on the results are presented.

Xie Xuemei, Zeng Saixing (2009) construct an impacting factor model of technology innovation of SMEs including 10 factors, such as financial capital, R\&D intensity, innovation network etc. Based on a survey with a sample of 188 SMEs in Shanghai and Shenzhen, this study explore the factors and mechanism impacting the technology innovation of SMEs by using Factor Analysis and Categorical Regression. The result indicates that 8 factors such as financial capital, R\&D intensity, technically qualified staffs, have positive effects on technology innovation of SMEs, and among which the effect of R\&D intensity and financial capital is most significant.

To sum up, only by strengthening technological innovation, accelerating scientific and technological progress, can we achieve great breakthroughs in some areas and realize a jump in technological development, ultimately promote China's modernization process.

\section{Problems of Technical Innovation in China}

With the economic globalization and the impact of network, China has attached more importance to technology innovation.

Rapid growth of industry itself shows that technological innovation has made remarkable achievements, but the shortage of China's overall innovation is still a very prominent problem in the process of China's industrial technology. In a certain sense, the high output, low level, weak technology, little creation are still the basic situation of enterprise development. The reasons for this are that main technical innovation not playing a leading role, the slow pace of transformation of economic growth mode, the slow pace of economic growth, so strong follow-up of Chinese technology innovation activities exist many problems. The reasons for this are main technical innovation which is not play a leading role, the slow pace of change about the transformation of economic growth mode, the lack of strong economic growth in the sustained momentum, so strong follow-up of Chinese technology innovation activities exist many problems.

\subsection{The insufficient input of funds for technological innovation and research and a lack of staff}

$\mathrm{R} \& \mathrm{D}$ innovation is the most important input factor for it creates new knowledge and products. The amount of funding for R \& D, to a certain extent, reflects the scale of technological innovation activities. The insufficient input of funds resulted in China's low innovation ability with low value-added products. The major force in technological innovation, the colleges and universities, does not play its due role. On the other hand, with the country enlarged enrollment in recent years, it can be seen the overall quality of college students, the reserve force of innovation, is in decline, which has slowed down influenced technology innovation progress.

\subsection{The low efficiency of technological innovation and low transformation rate}

At present, the process of scientific research and industry phase remain disjointed, on the one hand,

research institutions engaged in the research and development activities of hold a lot of research achievements, among which many cannot be changed into productive forces promptly. There are serious problem of idle scientific and technological achievements and waste of research resources. Scientific and technological achievements of unemployment and research situation of waste resources are very serious. On the other hand, many enterprises cannot find suitable technologies at home and had to import some from abroad at high cost. This phenomenon, the domestic research institutions will be attributed to its nature of scientific and technological achievements, leading to the results of science and technology maturity is too high, the unreasonable market demand of the maturity of their research results. But the enterprises blame the science and technology R\&D institutions for being unable to provide scientific and technological achievements with practical value, After these companies got the scientific and technological achievements, they often have to put in a great human, material and financial resources for secondary development, innovation and bear the risk of market and technology development.

\section{Analysis methods and the process}

\subsection{Data sources}

After the development of Chinese enterprises and multi-year demonstration, technical innovation of enterprises is affected by many factors, including the most important factors, government financial allocation and the number of scientific research. Therefore we analyze the top ten technology innovation policies during 1998 - 
2007 with data regression in Table 1.In order to analysis technology innovation policy play a role in the situation which on the road of Socialist market economy with Chinese characteristics, Thus we can find the enterprise technological innovation process where needs to be improved in China's future.

\section{Insert Table 1 Here}

\subsection{Multiple linear regression model steps}

\subsubsection{Hypothesis variables, to establish equation}

In reality, people tend to analyze a variable y statistically. Considering there are more than one independent variable related to variable $\mathrm{y}$, we need consider relationship between the variable $\mathrm{y}$ and the $\mathrm{p}$ variables $x_{1}, x_{2}, \ldots, x_{p}$. Return to the question above is the $\mathrm{p}$ element Regression.

Assume a random variable y has changes with $\mathrm{p}$ independent variables, The general multiple linear regression model is

$$
y=\beta_{0}+\beta_{1} x_{1}+\beta_{2} x_{2}+\ldots+\beta_{p} x_{p}+\varepsilon
$$

in which $\beta_{1}+\beta_{2}+\ldots+\beta_{p}$ for the regression coefficient, $\varepsilon$ is the variable about $N\left(0, \sigma^{2}\right)$. The first thing of regression analysis is to estimate the least square regression coefficients, and then to establish the regression equation; on the basis of the regression equation and the partial regression coefficient, significance test is carried out to determine whether the least square estimate of random variable y is consistent with the actual problem.

\subsubsection{Regression equation significance tests}

(1) Multiple linear regression analyses of variance

Multiple linear regression model is only an assumption. After obtaining the regression equation, it is also necessary to analyze the variance, to test the significance of linear relationship between $y$ and $x_{1}, x_{2}, \ldots, x_{p}$, that is to exam the assumption

$$
H_{0}: \beta_{1}=\beta_{2}=\ldots=\beta_{p}=0
$$

Then according to statistics

$F=\frac{S S_{R} / p}{S S_{e} /(n-p-1)}$ which is subject to (p, p-n-1) degrees of freedom on the F distribution, test whether equation (2) is justified. (Here, $S S_{R}=\sum_{k=1}^{n}\left(\hat{y}_{k}-\bar{y}\right)^{2}=\sum_{i=1}^{p} b_{i} l_{i y} ; S S_{e}=\sum_{k=1}^{n}\left(y_{k}-\hat{y}_{k}\right)^{2}$

(2) Partial regression coefficient significance tests

When $H_{0}$ was established, $t_{i}=b_{i} / \sqrt{S_{e}^{2} C_{i j}} \quad\left(\right.$ Here, $\left.S_{e}^{2}=\sqrt{S S_{e} /(n-p-1)}\right)$ is subject to (n-p-1) degrees of freedom about t-distribution.

Then the impact of selected factor $x_{i}$ is not significant on $\mathrm{y}$, otherwise, the impact is significant.

\subsection{Multiple regression analysis of data}

(1) According to the model building steps and combined with this data, the assuming variables are in Table 2

\section{Insert Table 2 Here}

(2) Multiple regression analysis with statistical software SPSS17.0, based on the above assumptions and analysis After operation, the results are gotten that $\mathrm{X} 3, \mathrm{X} 7, \mathrm{X} 8$ and $\mathrm{X} 9$, as the significance level, are greater than 0.05 , 
then the conclusion is reached that corresponding to the impact of the variable y not significant, therefore they are excluded. The remaining five variables: X1, X2, X4, X5, and X6 are more significant; obviously playing their roles in promoting scientific and technological progress. The results of regression analysis are in Table 3 .

\section{Insert Table 3 Here}

\section{Conclusions and Advices}

\subsection{Conclusion}

According to the above model it can be concluded that colleges as the major force in technological innovation do not play their due role. On the other hand, the overall quality of college students is in decline. Second, the model results show that $\mathrm{R} \& \mathrm{D}$ investment, especially investment in basic research on the impact of technological innovation is very significant. Thirdly, researchers for the implementation of technological innovation also played a very significant role. There are much more scientists and engineers in China than in any other developed countries, but it has not brought high quality scientific research.

\subsection{Advice}

(1) As for insufficient technical innovation and brain drain phenomenon, investment in education must be increased, education and training institutions should be improved, and personnel training, must be strengthened to improve the overall quality of scientific and technical personnel. Sound human resources incentives should be established, to attract and retain high-tech personnel.

Attention to high-tech personnel training, increasing investment in education, improving the overall quality of scientific and technical personnel.

(2) Strengthen education infrastructure investment, perfect technology innovation talent incentive mechanism, attract and retain talents. Through the use of government procurement policies to solve the problem of inefficient innovation and transformation rate, At the same time, we should make a full use of the role of intermediary service organizations, enhance cooperation between government research institutions and enterprises and improve the transformation rate about the efficiency and technological innovation and technological achievements.

(3) The enterprise should become the subject of technological innovation and the government should attract and support domestic enterprises to participate in some key technology researches and development tasks through its guiding polices

(4) The relationship between the industry, government, academy and research institutions should be strengthened and the long-term cooperation between the four should established to promote the industrialization of scientific and technological achievements, and at last, to promote industrial technology development of China.

\section{References}

Branzei O and Vertinsky L. (2006). Strategic pathways to product innovation capabilities in SMEs. Journal of Business Venturing, 21(1), 75-105.

Chen, Xiaohong and Han, Wenqiang. (2008). Empirical research on the Model for influencing factors of SMEs tech - innovation in China. Forum on Science And Science And Technology In China, 7, 74-78.

Chi, Renyong. (2003). Studies on Technical Innovation Efficiency of Enterprises and Its Affecting Factors. Quantitative and Technical Economics, 20, 105-108.

Diez MA. (2001). The evaluation of regional innovation and Cluster policies towards a participatory approach European. Planning Studies, 9, 901-923.

Du, Xiufang \& Yan, Xiaofei. (2008). On the regional technological innovation capacity based on factor analysis. Reformation \& Strategy, 24, 84-87.

Elenkov D. (2002). Effects of leadership on organizational performance Russian companies. Journal of Business Research, 55, 467-480.

Fan, Aijun \& Liu, Yunying. (2006). The quantitative analysis of our high technique industry technical innovation impact factor. Research on Economics and Management, 10, 58-62.

Fritsch M, (2002). Measuring the quality of regional innovation systems-a knowledge production function approach. International Regional Science Review, 25, 86-101.

Jiang, Yongkang. (2009). Study on influencing factors of technological innovation capability. Market Modernization, 563, 81-82. 
Liao, Xianglin and He, Jing. (2008). China's SME technology innovation strategy game of choice. Market Modernization, 7, 107-108.

Liu, Li. (2003). Factors Influencing a Firm's R\&D Investment: A Theoretical Analysis From the ResourceBased View. Forum on Science And Technology In China, 6, 75-77.

Shao, Yunfei \& Tang Xiao. (2006). Base on The linear demonstration analyses of Chinese technical innovation capacity. Management Review, 4, 12-21.

Sun, Ximing and Zhang, Jinglong. (2002). Study on enterprises technological innovation ability: Index based on complexity analysis. USA China Business Review, 3, 63- 66.

Xie, Hongming and Wang, Cheng. (2007). An empirical research of influencing technical innovation's factor. Studies In Science Of Science, 25, 963-969.

Xie, Xuemei and Zeng, Saixing. (2009). Measurement of factors impacting the technology innovation level based on categorical regression. Industrial Engineering And Management, 14, 81-83.

Zeng, Zhu. (2008). The analysis of technological innovation policy in America and its enlightenment to China. Journal of Gansu Lianhe University (Social Sciences), 24, 14-18.

Zhao, Yong \& Ye, Liang. (2007). Research on model of technology innovation capability evaluation of enterprise base on ridge regression. Machinery Design \& Manufacture, 10, 194-196.

Table 1. China Science and Technology Data from 1997 to 2008

\begin{tabular}{|l|l|l|l|l|l|l|l|l|l|l|}
\hline Year & $\mathrm{x} 1$ & $\mathrm{x} 2$ & $\mathrm{x} 3$ & $\mathrm{x} 4$ & $\mathrm{x} 5$ & $\mathrm{x} 6$ & $\mathrm{x} 7$ & $\mathrm{x} 8$ & $\mathrm{x} 9$ & $\mathrm{y} 1$ \\
\hline 1998 & 551.10 & 28.90 & 0.70 & 75.50 & 48.50 & 438.60 & 2949.10 & 57.20 & 40.70 & 67889 \\
\hline 1999 & 678.90 & 33.90 & 0.80 & 82.20 & 53.10 & 543.85 & 3349.00 & 63.50 & 44.60 & 100156 \\
\hline 2000 & 895.70 & 46.70 & 1.00 & 93.00 & 69.50 & 575.62 & 3848.10 & 76.70 & 49.40 & 105345 \\
\hline 2001 & 1024.50 & 52.50 & 1.07 & 95.70 & 74.30 & 575.62 & 4637.70 & 102.40 & 54.10 & 114251 \\
\hline 2002 & 1287.60 & 73.80 & 1.23 & 103.50 & 81.10 & 816.22 & 5480.00 & 130.50 & 56.80 & 132399 \\
\hline 2003 & 1539.60 & 87.70 & 1.31 & 109.50 & 86.20 & 944.60 & 6208.30 & 162.30 & 58.30 & 182226 \\
\hline 2004 & 1966.60 & 117.20 & 1.44 & 115.30 & 92.60 & 1095.30 & 7242.60 & 200.90 & 58.80 & 190238 \\
\hline 2005 & 2450.00 & 234.30 & 1.33 & 136.05 & 111.90 & 1334.90 & 8418.80 & 242.30 & 50.20 & 214003 \\
\hline 2006 & 3003.1 & 264.10 & 1.42 & 150.20 & 122.40 & 1688.50 & 9815.30 & 276.80 & 56.10 & 268002 \\
\hline 2007 & 3710.2 & 301.80 & 1.49 & 173.60 & 142.30 & 2113.50 & 12148.07 & 314.70 & 59.80 & 351782 \\
\hline
\end{tabular}

* Source: China Statistical Yearbook (1998 -2007), China Science and Technology Statistics (1998 -2007) 
Table 2. Data variable

\begin{tabular}{|l|l|l|}
\hline $\mathrm{x}$ & $\begin{array}{l}\text { X1 The total funding for research and experimental } \\
\text { development expenditures (billion) }\end{array}$ & $\begin{array}{l}\text { X6 The state financial expenditure } \\
\text { for scientific research (million) }\end{array}$ \\
\hline $\begin{array}{l}\text { X2 Applied and basic research R \& D expenditure } \\
\text { (million) }\end{array}$ & $\begin{array}{l}\text { X7 Education Investment (million) } \\
\text { X3 Research and experimental development expenses } \\
\text { of GDP ratio (\%) }\end{array}$ & $\begin{array}{l}\text { X8 Higher Education Research and } \\
\text { Experimental Development } \\
\text { Expenditure (million) }\end{array}$ \\
\hline & $\begin{array}{l}\text { X4 Research and Experimental Development } \\
\text { full-time equivalent staff (million per year) }\end{array}$ & $\begin{array}{l}\text { X9 Higher education students per } \\
\text { thousand population (person) }\end{array}$ \\
\hline & $\begin{array}{l}\text { X5 The number of scientists and engineers (million } \\
\text { per year) }\end{array}$ & $\begin{array}{l}\text { Y1 Patent application for authorization number } \\
\text { (pieces) }\end{array}$ \\
\hline$y$
\end{tabular}

Table 3. Test statistic results

\begin{tabular}{|l|l|l|l|l|l|}
\hline \multirow{2}{*}{ Model } & \multicolumn{2}{|l|}{$\begin{array}{l}\text { Unstandardized } \\
\text { Coefficients }\end{array}$} & $\begin{array}{l}\text { Standardized } \\
\text { Confficients }\end{array}$ & $\mathrm{t}$ & Sig \\
\cline { 2 - 5 } Constant & B & Std.Error & Beta & & \\
\hline X1 & 187699.3 & 71491.159 & & 2.625 & .058 \\
\hline X2 & 273.189 & 33.601 & 2.753 & 8.130 & .001 \\
\hline X4 & 6724.937 & 916.674 & 4.119 & 7.336 & .002 \\
\hline X5 & 7840.315 & 2324.987 & 2.107 & 3.372 & .028 \\
\hline X6 & 6119.212 & 1809.188 & 1.810 & 3.382 & .028 \\
\hline
\end{tabular}

